\title{
Switching strategies in complex transposition: Sometimes an arterial switch is not the answer
}

\author{
Nicholas D. Andersen, MD, ${ }^{\mathrm{a}}$ and Joseph W. Turek, MD, $\mathrm{PhD}^{\mathrm{b}}$
}

\footnotetext{
From the a Department of Cardiac Surgery, Boston Children's Hospital, Harvard Medical School, Boston, Mass; and ${ }^{\mathrm{b}}$ Division of Cardiovascular and Thoracic Surgery, Duke University Medical Center, Durham, NC. Disclosures: Authors have nothing to disclose with regard to commercial support.

Received for publication May 22, 2018; revisions received May 22, 2018; accepted for publication May 23, 2018; available ahead of print July 4, 2018.

Address for reprints: Nicholas D. Andersen, MD, Department of Cardiac Surgery, Boston Children's Hospital, 300 Longwood Ave, Bader 273, Boston, MA 02115 (E-mail: Nicholas.Andersen@ cardio.chboston.org). J Thorac Cardiovasc Surg 2018;156:e191-2

$0022-5223 / \$ 36.00$

Copyright (C) 2018 by The American Association for Thoracic Surgery https://doi.org/10.1016/j.jtcvs.2018.05.092
}

The technique for arterial-level repair of transposition of the great arteries (TGA) without coronary artery transfer was described separately by Damus, Stansel, and Kaye in the early 1970s. The concept was initially viewed as superior to the atrial-level switch operations (Mustard or Senning), because it achieved ventriculoarterial concordance with the left ventricle serving as the systemic ventricle. The other benefit of the Damus-Kaye-Stansel (DKS) approach was

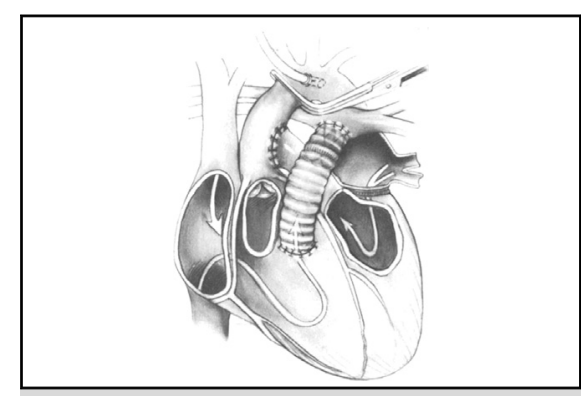

Damus-Kaye-Stansel: an old technique finds new life for repair of complex transposition.

\section{Central Message}

Anatomic repair of transposition of the great arteries without coronary transfer is an important technique for patients with transposition and complex coronary artery anatomy.

See Article page e189.

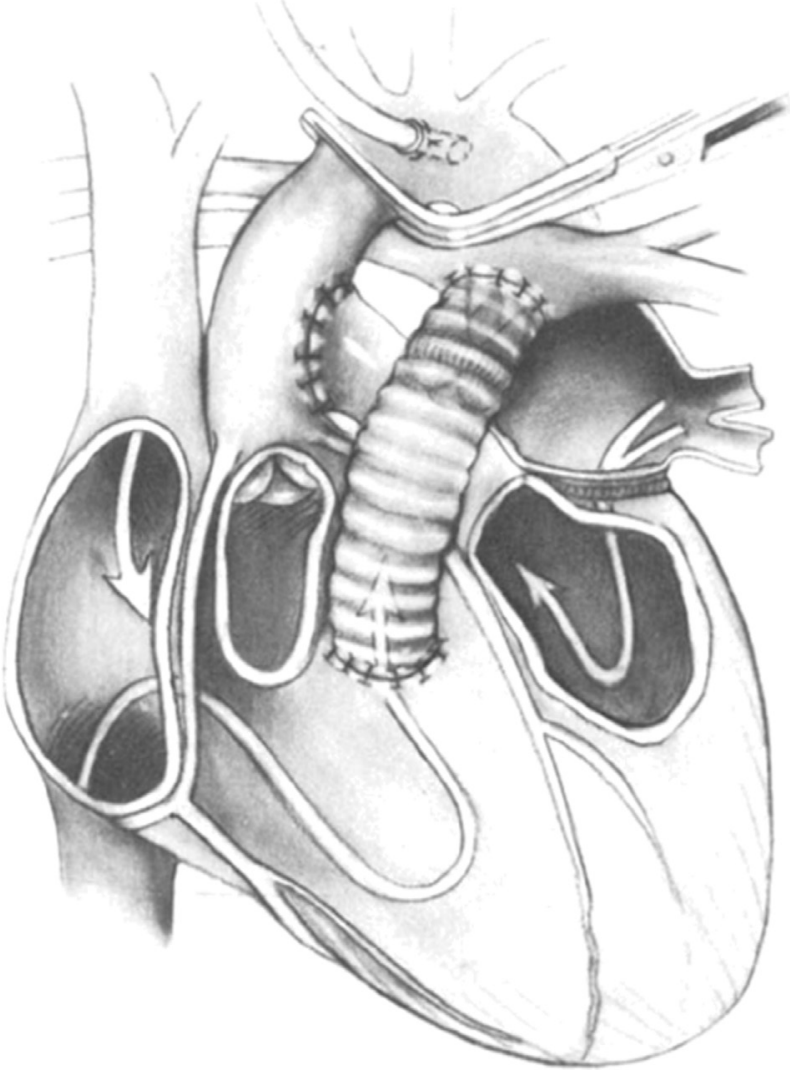

FIGURE 1. Damus-Kaye-Stansel: an old technique finds new life for repair of complex transposition. Reprinted with permission. ${ }^{1}$ avoidance of difficult coronary transfers. As experience with the Jatene operation, Lecompte maneuver, and coronary artery transfer proliferated, however, the DKS repair of TGA quickly fell out of favor, because complete anatomic repair of TGA could be achieved safely in most instances without the lifelong morbidity of a right ventricle-pulmonary artery conduit. ${ }^{1}$

In the current issue of the Journal, Kumar and colleagues $^{2}$ have cleverly resurrected an old technique (Figure 1) to tackle a complex TGA variant with doubleoutlet right ventricle, subpulmonic ventricular septal defect, side-by-side great vessels, and a previously unreported coronary artery pattern involving a common origin of the right coronary artery and the left anterior descending artery from the nonfacing sinus. Kumar and colleagues ${ }^{2}$ did not consider coronary transfer was feasible in this case given the distance of the coronary artery from the neo-aorta, as well as the depth of the coronary ostia within the nonfacing sinus. Instead, a DKS-Rastelli repair was performed to achieve anatomic correction without manipulation of the coronary arteries.

This case report is notable for 2 reasons: (1) a previously unreported coronary artery pattern is described and, (2) $\mathrm{Ku}$ mar and colleagues ${ }^{2}$ dug deep into the congenital heart surgeons' toolbox and dusted off an old technique to repair a rare lesion safely. Although the temptation to perform a standard repair without a right ventricle-pulmonary artery 
conduit was likely present, Kumar and colleagues ${ }^{2}$ demonstrated restraint and creativity in choosing the DKS-Rastelli technique. It is probably a stretch, however, to claim that a coronary transfer would have been completely impossible in this instance. Coronary artery relocation from a remote nonfacing sinus has been described in many cases of anomalous left coronary artery from the pulmonary artery. Tubularization or coronary artery lengthening procedures can be performed even in instances in which the ectopic coronary arises from deep within the nonfacing sinus. In these cases, instead of harvesting a horizontal strip of aorta or pulmonary artery as a long coronary button, the button extension is instead harvested vertically. The resulting long button can then be tubularized directly or augmented with a patch to create an autologous coronary tunnel to the aorta. ${ }^{3}$ In addition to the Takeuchi repair, other strategies can include interposition grafting with a harvested segment of common carotid artery, or left or right subclavian artery turndown to revascularize the remote coronary button. ${ }^{4}$ Finally, if the ventricular septal defect and left ventricle to aorta pathway were large and unrestrictive, a Rastelli repair alone without DKS might have been sufficient.
Nonetheless, the DKS-Rastelli repair shown here was undoubtedly a good choice for this patient, and this case serves as an important reminder that TGA can be safely repaired without coronary transfer, even in patients with an intact ventricular septum. Although the use of a right ventriclepulmonary artery conduit may be viewed by some surgeons as a failure, we can all agree that loss of life from a botched coronary transfer is an even greater failure.

\section{References}

1. Ceithaml EL, Puga FJ, Danielson GK, McGoon DC, Ritter DG. Results of the Damus-Stansel-Kaye procedure for transposition of the great arteries and for double-outlet right ventricle with subpulmonary ventricular septal defect. Ann Thorac Surg. 1984;38:433-7.

2. Kumar TKS, Amin N, Sathanandam S, Knott-Craig CJ. Management of coronary artery arising from non-facing sinus in transposition of great arteries. J Thorac Cardiovasc Surg. 2018;156:e189-90.

3. Kaewsaengeak C, Tocharoenchok T. Superior pulmonary arterial flap for the repair of the left coronary artery from the non-facing pulmonary sinus. Interact Cardiovasc Thorac Surg. 2018;26:902-5.

4. Kesler KA, Pennington DG, Nouri S, Boegner E, Kanter KR, Harvey L, et al. Left subclavian-left coronary artery anastomosis for anomalous origin of the left coronary artery. Long-term follow-up. J Thorac Cardiovasc Surg. 1989; 98:25-9. 